\title{
Optimal Planning of a Distribution Network in Egypt
}

\author{
Asmaa F. Nasef, Heba A. Khattab, and Dina S. Osheba \\ Department of Electrical Engineering, Menoufia University, Shebin El Kom, Egypt. \\ (Corresponding author: ASMAA.NASEF@sh-eng.menofia.edu.eg)
}

\begin{abstract}
Distribution networks planning is a very complex task as it involves the consideration of various important issues. A model for optimal planning of a distribution network is presented in detail, using Distributed Generation (DG). This paper presented a detailed analysis of the West Delta Network (WDN) as a part of the Egyptian distribution network with a $30 \%$ increase in system loading. An Oscillatory Particle Swarm Optimization (OPSO) technique was used to find the optimal locations and sizes of one DG or multiple DGs for achieving the objectives of minimizing total active power losses and system voltage regulation as a single-and-multi-objective optimization problem in a distribution network. Several penetration scenarios have done to evaluate concentrated (at one location) and distributed DGs (at different locations). The results are presented in a comparative form and thoroughly discussed. The obtained results will help in system operation with DG integration and identifying the critical penetration levels for the studied system.
\end{abstract}

Keywords: distributed generator (DG); Optimal DG location and size; Oscillatory PSO (OPSO); WDN.

\section{Introduction}

Distribution networks planning is a very complex task as it involves the consideration of various important issues including costs of different origin, technical and ambient imposed constraints and customer needs concerning the quality of energy delivery [1]. Traditionally, the planning models determine the optimal expansion decisions related to the increase of installation of branches, substations, and transformers [2, 3]. However, the spreading growth of distributed generation (DG), mainly due to its numerous planning and operational benefits [4], necessarily requires the inclusion of this kind of generation in distribution planning models [5]. The DG units can be considered the most suitable enhancement devices for distribution systems that reducing the total power losses, reducing green-house gas emission, improving the voltage profile and system reliability, if they are optimally sized and sited [6-8]. So, there has been a significant rise in interest by researchers to develop methods to find the optimal DG location and size for integrating into the networks.

Major technical approaches for optimal DG allocation are categorized as analytical approach, classical (non-heuristic) approach, meta-heuristic optimization approach, hybrid approach and assorted approaches [9, 10]. Analytical techniques are used efficiently for small and simple systems, but are not suitable for a large systems and complex networks
$[11,12]$. However, various meta-heuristic techniques are performing better for extensively large and complex networks in terms of accuracy, convergence and they can help to find near optimal solutions in a more efficient way. The most popular optimization approaches for DGs allocation are Genetic Algorithm (GA) [13], Particle Swarm Optimization (PSO) [14], Ant Colony Optimization (ACO) [15], Harmony Search (HS) [16], Simulated Annealing (SA) [17], Tabu Search (TS) [18], Artificial Bee Colony (ABC) [4], Bat algorithm [19], Ant line optimization [20], Firefly algorithm [21] and Cuckoo Search (CS) [22]. In this paper, an OPSO algorithm was applied to find the optimal DGs allocation for optimal planning to WDN as a part of a real distribution system considering two objectives: minimizing total active power losses, minimizing voltage regulation as a single-and-multi-objective optimization problem while the equality and inequality constraints are satisfied. A comparison between the system performance using concentrated and distributed DG is presented, illustrating its impacts on system performance (system losses and voltage regulation).

\section{Case study: real system}

The WDN distribution system is considered in this work which is a part of the Egyptian unified network. This network consists of 52-bus and 8 generators connected by 108 lines as shown in Fig. 1with the data given in [23, 24]. However, the original system 


\section{Asmaa F. Nasef, Heba A. Khattab, Dina S. Osheba "Optimal Planning of a Distribution Network in Egypt"}

is modified by increasing the loads in the system by $30 \%$. So, the loads become $1156.68 \mathrm{MW}, 701.98$ MVAR while generation are 1201.75 MW, 587.57 MVAR. This modification increases total active power losses from 20.37 MW to 45.07 MW, voltage regulation from $8.69 \%$ to $11.47 \%$. This leads to severe deterioration in voltage profile especially at buses 18, $20 \& 32$ (under the minimum limit of bus voltage) as shown in Fig. 2, while the minimum and maximum limits of voltages at all buses are 0.94 and 1.06 , respectively (the base voltage is $66 \mathrm{kV}$, whereas the base MVA is 100).

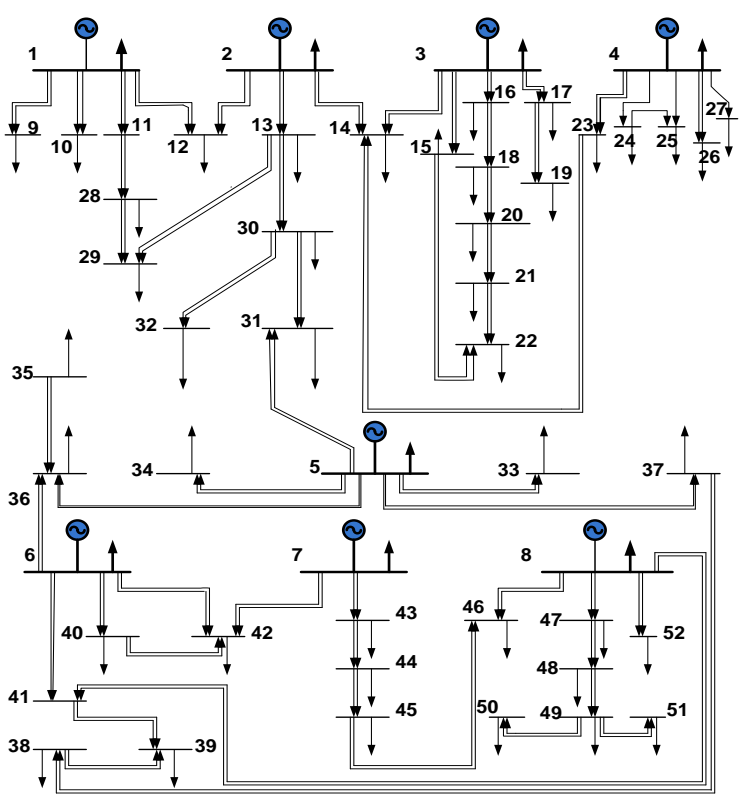

Fig. 1 Single-line diagram of WDN

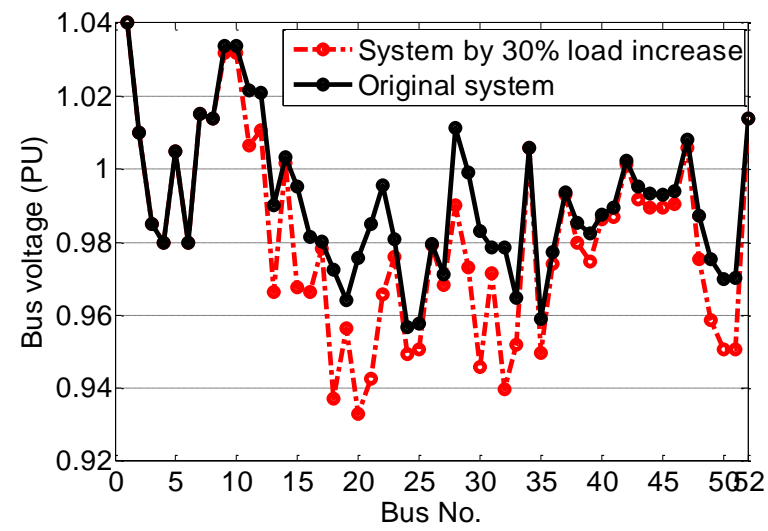

Fig. 2 Impact of load increasing on voltage profile of WDN

\section{Problem formulation}

The DG optimal allocation problem is treated as an optimization problem and is solved using the recently developed OPSO. The problem considered the minimization of total active power losses (F1) [25], voltage regulation (F2) [26], each objective is considered firstly as a single objective and secondly, the two objectives are solved as a multi-objective optimization problem with different weightings according to (3) [27].

$$
\begin{aligned}
& F_{1}=\min \sum_{i, j \in N_{b}} g_{i j}\left(V_{i}^{2}+V_{j}^{2}-2 V_{i} V_{j} \cos \theta_{i j}\right) \\
& F_{2}=\min \left(\frac{V_{i m a x} V_{i m i n}}{V_{i m i n}} * 100\right) \\
& F_{3}=\min \left(W_{1} * F_{1} /_{F_{1 b a s e}}+W_{2} * F_{2} /_{F_{2 b a s e}}\right)
\end{aligned}
$$

Where $W_{1}+W_{2}=1$, each weight $W_{k} \in[0,1]$ and F1base, F2base are the total active power losses and voltage regulation index for the system without DG. $\mathrm{Nb}$ is the number of system buses; gij is the conductance of the transmission lines between buses $i$ and $\mathrm{j}$; $\mathrm{Vi}$ and $\mathrm{Vj}$ are the voltage magnitude at buses $\mathrm{i}$ and $\mathrm{j}$, respectively; and $\theta \mathrm{ij}$ is the angle difference between buses $\mathrm{i}$ and $\mathrm{j}$.

The above problem is subjected to the following optimization equality and inequality constraints:

$$
\begin{aligned}
& P_{G i}+P_{D G i}-P_{L i}=V_{i} \sum_{j=1}^{N_{b}} V_{j}\left(G_{i j} \cos \theta_{i j}+\right. \\
& \left.B_{i j} \sin \theta_{i j}\right) \\
& Q_{G i}-Q_{L i}=V_{i} \sum_{j=1}^{N_{b}} V_{j}\left(G_{i j} \sin \theta_{i j}-B_{i j} \cos \theta_{i j}\right)
\end{aligned}
$$

$Q_{G i}^{\min } \leq Q_{G i} \leq Q_{G i}^{\max }, i=1,2 \ldots, N_{v}$

$P_{D G i}^{\min } \leq P_{D G i} \leq P_{D G i}^{\max }, i=1,2 \ldots, N_{D G s}$

$V_{i}^{\min } \leq V_{i} \leq V_{i}^{\max } \quad, i=1,2 \ldots, N_{b}$

$\left|S_{i}^{\text {flow }}\right| \leq S_{i}^{\max } \quad, i=1,2 \ldots N_{L}$

where $\mathrm{P}_{\mathrm{Gi}}$ and $\mathrm{Q}_{\mathrm{Gi}}$ are the active and reactive power generated at bus $\mathrm{i}$, respectively; $\mathrm{P}_{\mathrm{Li}}$ and $\mathrm{Q}_{\mathrm{Li}}$ are the active and reactive power of the load at bus $\mathrm{i}$, 


\section{Asmaa F. Nasef, Heba A. Khattab, Dina S. Osheba "Optimal Planning of a Distribution Network in Egypt"}

respectively; $\mathrm{P}_{\mathrm{DGi}}$ is the active power generated from the DG unit at bus $i$ and $G_{i j}$ and $B_{i j}$ are the mutual conductance and susceptance between buses $\mathrm{i}$ and $\mathrm{j}$, respectively; $\mathrm{Nv}$ refers to the total number of voltage-controlled buses, NDGs refers to the number of DG buses, $S^{\text {flow }}$ is the apparent power flow, Smax is the MVA maximum of the lines and transformers. Superscripts min and max are the lower and upper limits of the interested variable.

\section{Optimization technique}

PSO is a population-based stochastic search algorithm because of its simple implementation, it can converge to the optimal solution in several problems where most analytical approaches fail to converge and is more effective in preserving the variety of the swarm since all particles use the information related to the most successful particle in order to improve them [28]. Due to these features and other features, other techniques of PSO are introduced such as: Selective Particle Swarm Optimization algorithm (SPSO) [29], Improved PSO Based on Success Rate (IPSO-SR) [30], Distance based Intelligent PSO (DbIPSO) [31] and other techniques. Recently, the particle has been derived into oscillatory trajectories such that the search space can be covered more completely from high to low dimensions leading to Oscillatory PSO (OPSO) which is a modified version of PSO [32]. It performs an analysis based on the difference equation to detect conditions that guarantee trajectory oscillation and fast solution convergence. In OPSO, the particle position and velocity are updated using the following difference equation:

$$
\begin{gathered}
x_{T+1}^{j, d}=x_{T}^{j, d}+w\left(x_{T}^{j, d}-x_{T-1}^{j, d}\right)+\cdots \\
c_{1}\left(p b_{T}^{j, d}-x_{T}^{j, d}\right)+c_{2}\left(g b_{T}^{j, d}-x_{T}^{j, d}\right) \\
V_{T}^{j, d}=x_{T}^{j, d}-x_{T-1}^{j, d}
\end{gathered}
$$

Where, $\mathrm{v}^{\mathrm{j}, \mathrm{d}}$ and $\mathrm{x}^{\mathrm{j}, \mathrm{d}}$ are the velocity and position of the particle; $p b_{T}^{j, d}$ and $g b_{T}^{j, d}$ are the personal best position of individual particle $\mathrm{j}$ and global best position of all particles; $\mathrm{T}$ is referred to iteration number; $\mathrm{j}$ denotes the $\mathrm{jth}$ particle in the swarm of $\mathrm{M}$ particles, $\mathrm{d}$ denotes the dth dimension of the particle; $\mathrm{W}$ is the inertia weight; $\mathrm{c}_{1}$ and $\mathrm{c}_{2}$ are random cognitive and social learning factors and often equal 2. PSO and OPSO are executed on the WDN distribution network to find the optimal DG location and size. Table 1 shows a comparison between the results obtained from PSO and OPSO and Fig. 3 shows the conversion characteristic of OPSO and PSO which demonstrate the effectiveness of using the OPSO than PSO due to the previous mentioned advantages.

Table 1- Comparison between PSO and OPSO

\begin{tabular}{|c|c|c|c|}
\hline & PSO Without & PSO & OPSO \\
\hline DG location & & 44 & 44 \\
\hline $\begin{array}{c}\text { DG size } \\
(\mathrm{MW})\end{array}$ & 104.62 & 103.85 \\
\hline $\begin{array}{c}\text { Power losses } \\
(\mathrm{MW})\end{array}$ & 45.0725 & 16.7491 & 16.7457 \\
\hline
\end{tabular}

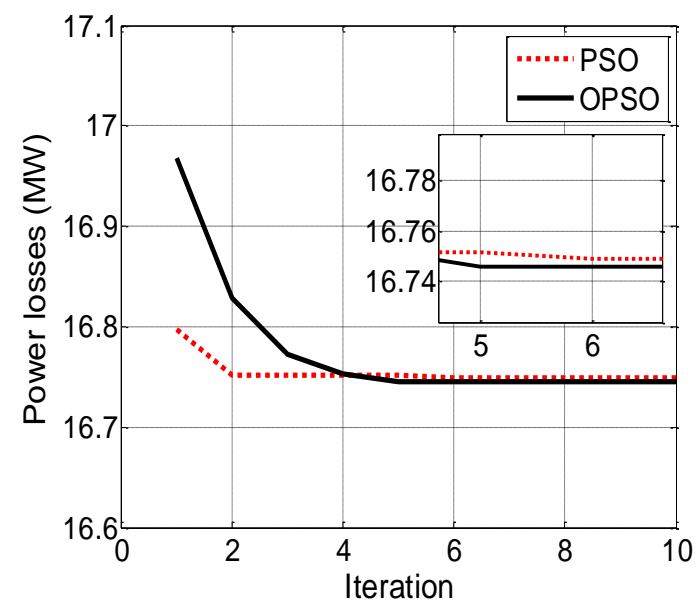

Fig. 3 Convergence characteristics of PSO and OPSO

\section{Simulation results and discussion}

The OPSO optimization algorithm is applied to obtain the optimal location and size of the DG in the WDN and the following scenarios have been considered:

Scenario 1: In this scenario, the minimum and maximum limits for the DG penetration level are 5 MW and 360 MW (by about 30\%). The OPSO algorithm is implemented to find the optimal DG location and size in case of concentrated at one location or distributed at several locations. Table 2 summarizes the optimal allocation of the DG. The following two cases have been considered to find the optimal allocation based on minimizing total active power losses (case 1) and minimizing voltage regulation (case 2 ) at each case the voltage deviation index is calculated from (12) [33]. 


$$
V D I=\sum_{i=1}^{N_{b}} \frac{\left|V_{\text {rated }}-V_{i}\right|}{V_{\text {rated }}}
$$

Where $V_{\text {rated }}$ is the rated voltage and equal $1 \mathrm{pu}$. The minimum value of VDI is preferred.

These results illustrating the following points:

- Optimal allocation based on minimizing the total active powerlosses, case-1, reduces the total active power losses by about $62.85 \%, 72.93 \%$ and $72.48 \%$ using one, two and three units respectivelycompared with the base case as shown in Fig. 4. Voltage regulation remains constant at $11.47 \%$ using one unit, decreased to $9.53 \%$ using two units and reached $10.17 \%$ using three units. The VDI decreased with increasing the units until two units and then increase with the three units.

- Optimal allocation based on minimizing the voltage regulation, case- 2 , reduces the voltage regulation from $11.47 \%$ to $9.65 \%, 9.53 \%$ and $9.44 \%$ using one, two and three units, respectively as shown in Fig. 5. The total active power losses in case of one unit increased to a value of $47.87 \mathrm{MW}$ which is greater than the base case. The total active power losses decreased by small percentages (3.35\% and $22.25 \%)$ using two and three units respectively compared with the base case. The VDI decreased with increasing the units.

- Regarding the reduction of system losses, the optimal location is bus-44; but for the reduction of voltage regulation the optimal location is bus-18 in case of concentrated at one unit.

- Fig. 6 shows the system voltage profile for the base case and one unit of case 1 and case 2. This figure shows, that the voltage profile has been improved with integrating the DG in bus-18 (case 2).

- Figs. 7 and 8 show the convergence characteristics of total active power losses minimization (one unit of case-1) and voltage regulation minimization (one unit of case-2), respectively which make sure that the OPSO technique has excellent convergence characteristics.
Table 2- summary of optimal DG allocation

\begin{tabular}{|c|c|c|c|c|c|c|}
\hline 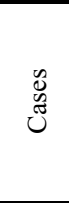 & 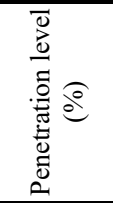 & 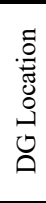 & 惫引 & 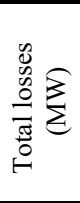 & $\bar{\rho}$ & 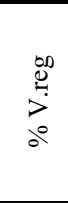 \\
\hline Base & & No & & 45.07 & 1.39 & 11.47 \\
\hline \multirow{6}{*}{$\begin{array}{l}\overline{0} \\
\tilde{\Xi} \\
\tilde{\Xi}\end{array}$} & $\begin{array}{l}\text { One unit } \\
(\% 8.64)\end{array}$ & 44 & 103.85 & 16.74 & 1.25 & 11.47 \\
\hline & \multirow{2}{*}{$\begin{array}{l}2 \text { units } \\
(\% 12.49)\end{array}$} & 20 & 57.65 & \multirow{2}{*}{12.20} & \multirow{2}{*}{1.09} & \multirow{2}{*}{9.53} \\
\hline & & 44 & 92.55 & & & \\
\hline & \multirow{3}{*}{$\begin{array}{c}\text { Three } \\
\text { units } \\
(\% 13.29)\end{array}$} & 44 & 90.48 & \multirow{3}{*}{12.40} & \multirow{3}{*}{1.15} & \multirow{3}{*}{10.17} \\
\hline & & 24 & 31.52 & & & \\
\hline & & 15 & 37.82 & & & \\
\hline \multirow{6}{*}{$\begin{array}{l}N \\
\tilde{z} \\
\tilde{E} \\
\tilde{z}\end{array}$} & $\begin{array}{l}\text { One unit } \\
(\% 17.17)\end{array}$ & 18 & 206.44 & 47.87 & 1.11 & 9.65 \\
\hline & Two & 18 & 200.17 & \multirow{2}{*}{43.56} & \multirow{2}{*}{1.09} & \multirow{2}{*}{9.53} \\
\hline & (\%17.85) & 31 & 14.44 & & & \\
\hline & \multirow{3}{*}{$\begin{array}{l}\text { Three } \\
\text { units } \\
(\% 20.92)\end{array}$} & 22 & 176.98 & \multirow{3}{*}{35.04} & \multirow{3}{*}{1.02} & \multirow{3}{*}{9.44} \\
\hline & & 25 & 35.20 & & & \\
\hline & & 50 & 39.24 & & & \\
\hline
\end{tabular}

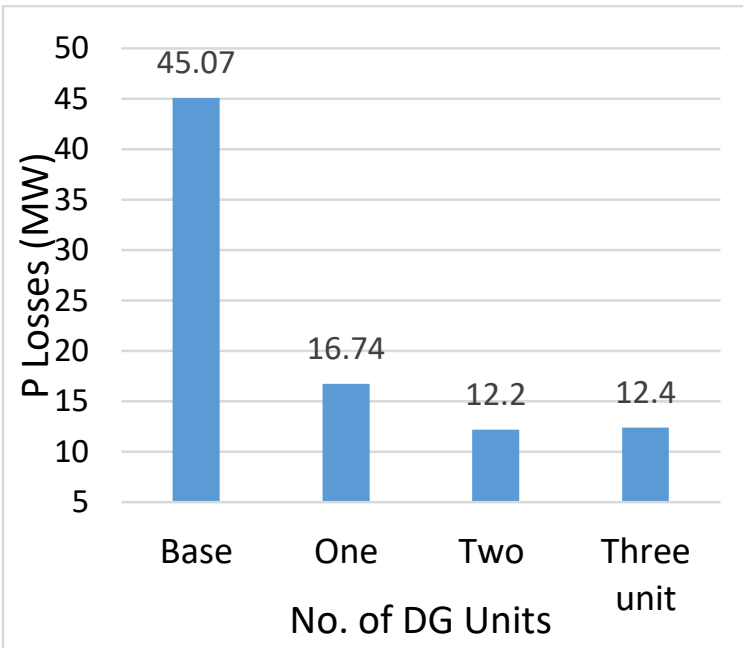

Fig. 4- Total active power losses for Case 1 


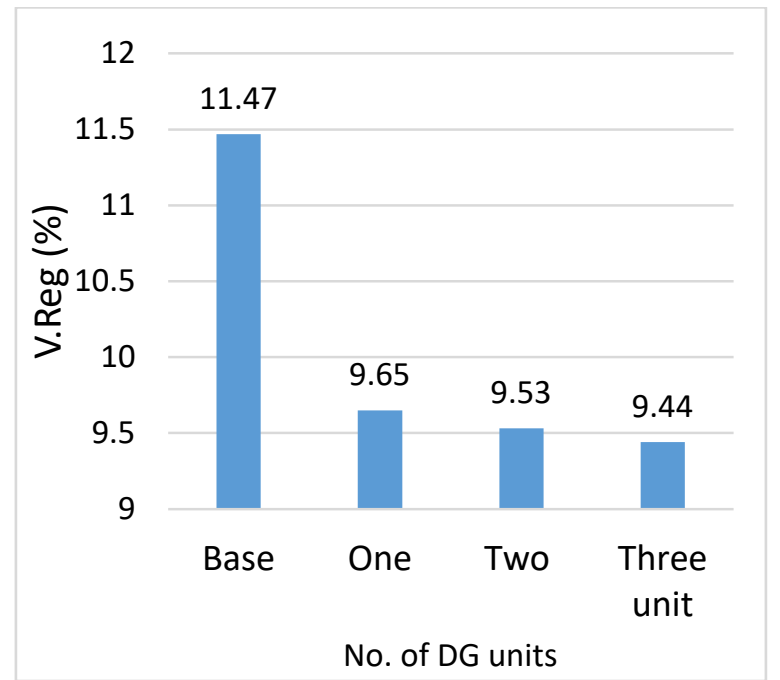

Fig. 5- Voltage regulation for Case 2

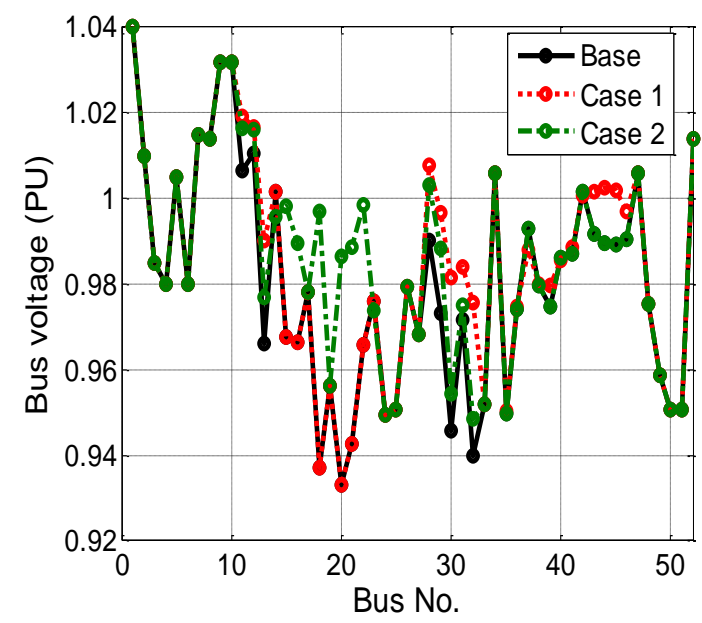

Fig. 6- System voltage profile for base case, case 1 and case 2(one unit)

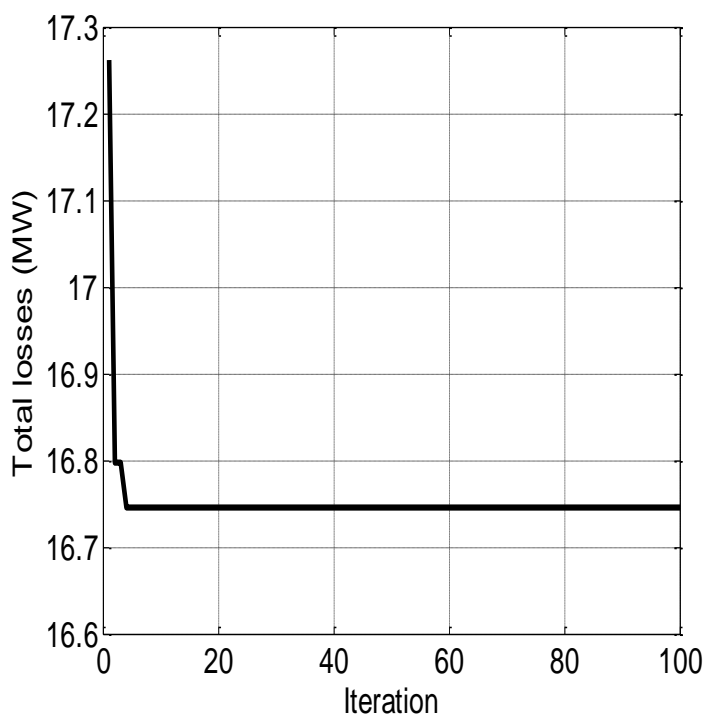

Fig. 7- Convergence characteristic of case 1 (one unit)

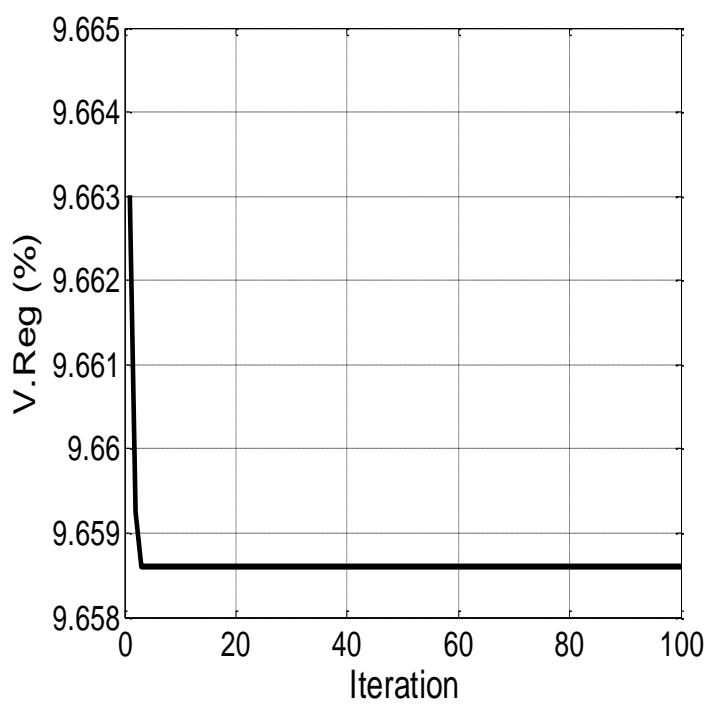

Fig. 8 Convergence characteristic of case 2 (one unit)

Scenario-2: The optimization problem is solved as a multi-objective problem by weighted sum method as in (3), case 3. Table 3 shows the results of minimizing the weighted multi-objective by OPSO algorithms. This table shows the values of objective functions (total active power losses (F1) and voltage regulation (F2)) and the according DG allocation for all 9 optimal solutions. The objective F1 is inversely proportional to objective F2. To minimize the F1, put the DG at bus-44 but to minimize the F2, put the DG at bus- 20 
Table 3- Results of minimizing the weighted multiobjective using OPSO

\begin{tabular}{|c|c|c|c|c|c|c|}
\hline \# & $\mathrm{W}_{1}$ & $\mathrm{~W}_{2}$ & $\begin{array}{l}\text { TOTAL } \\
\text { LOSSE } \\
\mathrm{S}\left(\mathrm{F}_{1}\right) \\
(\mathrm{MW})\end{array}$ & $\begin{array}{r}\text { V.reg } \\
\left({ }_{2} \mathrm{~F}\right) \\
(\%)\end{array}$ & 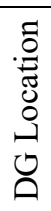 & $\begin{array}{l}\stackrel{N}{\infty} \\
\circlearrowright \\
己\end{array}$ \\
\hline 1 & 1 & 0 & 16.74 & 11.47 & 44 & 103.85 \\
\hline 2 & 0.8 & 0.2 & 16.74 & 11.47 & 44 & 103.85 \\
\hline 3 & 0.6 & 0.4 & 16.74 & 11.47 & 44 & 103.85 \\
\hline 4 & 0.5 & 0.5 & 16.74 & 11.47 & 44 & 103.85 \\
\hline 5 & 0.4 & 0.6 & 16.74 & 11.47 & 44 & 103.85 \\
\hline 6 & 0.3 & 0.7 & 16.74 & 11.47 & 44 & 103.85 \\
\hline 7 & 0.2 & 0.8 & 33.68 & 9.81 & 20 & 113.68 \\
\hline 8 & 0.1 & 0.9 & 35.09 & 9.75 & 20 & 131.74 \\
\hline 9 & 0 & 1 & 53.13 & 9.65 & 22 & 211.7 \\
\hline
\end{tabular}

For this analysis, total active power losses have the higher weight, since it is important in many applications of DG and it has direct impact on the system economy so, the weights were selected as follow: $\mathrm{w}_{1}=0.6, \mathrm{w}_{2}=0.4$. Table 4 shows the results of optimal DG allocation in case of concentrated at one unit and distributed at two or three units for case 3 .

This result illustrating:

The total active power losses reduced by about $62.85 \%, 69.27 \%$ and $74.21 \%$ using one, two and three units respectively compared with the base case. Voltage regulation remains constant at $11.47 \%$ using one unit, decreased to $9.53 \%$ using two units and reached $9.53 \%$ using three units. The VDI decreased with increasing the units
Table 4- Results of multi-objective case

\begin{tabular}{|c|c|c|c|c|c|c|}
\hline $\begin{array}{l}\tilde{y} \\
\tilde{z} \\
\tilde{u}\end{array}$ & 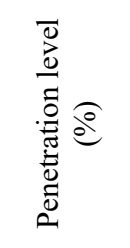 & 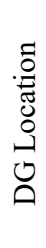 & $\begin{array}{l}\stackrel{N}{\infty} \\
0 \\
0 \\
0\end{array}$ & $\begin{array}{l}\sum \\
\sum \\
0 \\
0 \\
0 \\
0 \\
0 \\
0 \\
0 \\
0\end{array}$ & $\bar{\rho}$ & $\begin{array}{l}0_{0}^{00} \\
\stackrel{0}{7} \\
> \\
0\end{array}$ \\
\hline Base & & No & & 45.07 & 1.4 & 11.47 \\
\hline \multirow{6}{*}{$\begin{array}{l}n \\
\tilde{z} \\
\tilde{z} \\
\tilde{U}\end{array}$} & $\begin{array}{l}\text { One unit } \\
(\% 8.64)\end{array}$ & 44 & 103.8 & 16.74 & 1.2 & 11.47 \\
\hline & Two & 44 & 91.78 & \multirow{2}{*}{13.85} & \multirow{2}{*}{1.1} & \multirow{2}{*}{9.53} \\
\hline & $\begin{array}{l}\text { units } \\
(\% 12.92)\end{array}$ & 15 & 63.58 & & & \\
\hline & \multirow{3}{*}{$\begin{array}{c}\text { Three } \\
\text { units } \\
(\% 12.77)\end{array}$} & 44 & 88.91 & \multirow{3}{*}{11.62} & \multirow{3}{*}{1.1} & \multirow{3}{*}{9.53} \\
\hline & & 20 & 55.34 & & & \\
\hline & & 33 & 9.23 & & & \\
\hline
\end{tabular}

Scenario-3:Comparison between concentrated (CDG) and distributed (D-DG) DGs with different penetration levels as shown in Fig. 9. Figs. 9a, 9b show the total active power losses and the voltage regulation versus penetration level respectively. These Figures show the comparison between three cases: when C-DG is connected to bus-44 or bus-20 and DDG between buss-44, 20 and demonstrates that;

- For all penetration levels, the DG location at bus44 is better than bus-20 from the view point of minimizing total active power losses, but when look to the voltage regulation, bus-20 becomes more suitable than bus-44.

- At low penetration levels up to $10 \%$, both C-DG and D-DG produce the same active power losses while at high penetration levels, D-DG is better than C-DG. From the point view of Fig. 9b, the voltage regulation decreased when DG concentrated at bus-20 until $25 \%$ penetration level and also it decreased in case of distributed DG between the two buses.

- At all penetration levels the D-DG is better than the C-DG as it has minimum active power losses and voltage regulation. The results confirmed that there is an optimal penetration level for minimum losses and voltage regulation, and after this level the performance of the system turns to be bad and these factors increase again. 


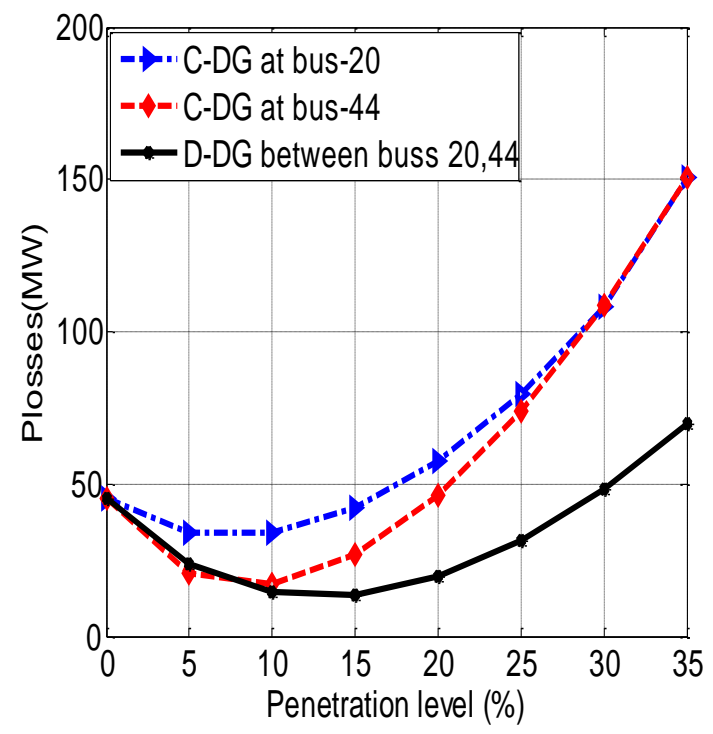

(a) Total active power losses versus penetration level

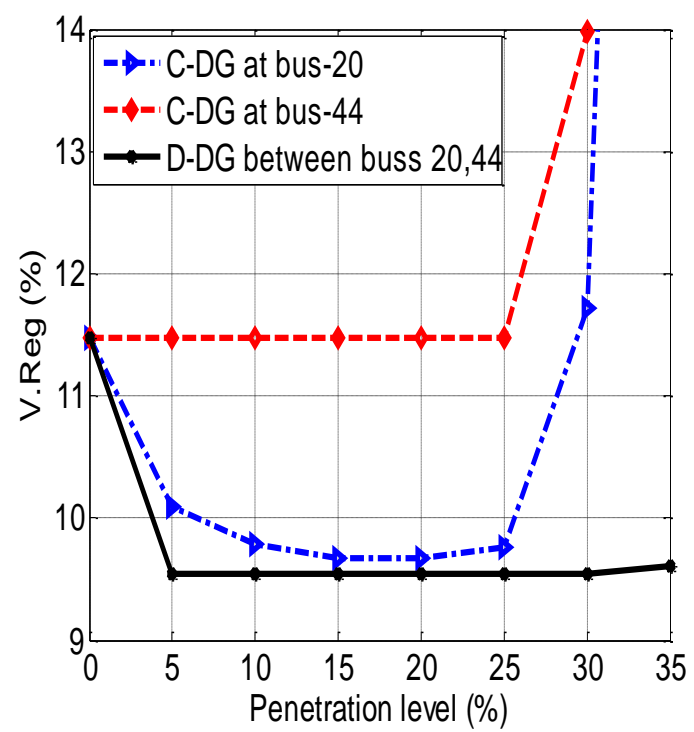

(b) Voltage regulation versus penetration level

Fig. 9- Impact of C-DG and D-DG integration on system performance

\section{Conclusions}

The optimal planning of a part of a distribution network in Egypt was solved by using DG units. OPSO has been used to solve the problem of finding the optimal DG sites and sizes due to its various advantages that include fast convergence characteristics of the fitness function and capabilities for treating complex problems. The effectiveness of the proposed technique is tested on the West Delta
Network (WDN) as a part of the Egyptian unified network with $30 \%$ increase in system loading. The OPSO is used to minimize total active power losses, minimize voltage regulation where each objective is treated as a single objective and when the allocation problem is treated as a multiobjective. The results illustrated that optimal allocation of DG leads to reduce the active power losses, improve voltage regulation and minimize voltage deviation. It has been demonstrated that the first objective used led to the optimum site which is bus-44, the second objective used led to the optimum site which is bus20 or 18 when considering concentrated DG at one site. Also, in distributed DG increasing the number of locations reduces the active power losses until a certain number and then increase again. Several cases were studied to differentiate between C-DG and DDG. For low penetration levels, the C-DG is better than the D-DG but with small difference. For high penetration levels, the D-DG is better than the C-DG in terms of minimizing active power losses as well as voltage regulation. The results presented in the paper are of importance to electric power system engineers forming a good based during the planning and operation stages.

\section{References}

[1] J. M. Nahman, and D. M. Peric, "Optimal Planning of Radial Distribution Networks by Simulated Annealing Technique", IEEE Trans. Power Syst., vol. 33, pp. 790-795,2008.

[2] H. L. Willis, "Power Distribution Planning Reference Book", 2nd ed. New York, NY, USA: Marcel Dekker, Inc., 2004.

[3] P. S. Georgilakis, and N. D. Hatziargyriou, “A review of power distribution planning in the modern power systems era: Models, methods and future research", Electric Power Systems Research, vol. 121, pp. 89-100, 2015.

[4] W. El-Khattam, Y. G. Hegazy, and M. M. A. Salama, "An integrated distributed generation optimization model for distribution system planning," IEEE Trans. Power Syst., vol. 20, no. 2, pp. 1158-1165, 2005.

[5] A. Keane, L. F. Ochoa, C. L. T. Borges, et al. , "State-of-the-art techniques and challenges ahead for distributed generation planning and optimization", IEEE Trans. Power Syst., vol. 28, no. 2, pp. 1493-1502, 2013.

[6] D. Huang, H. Li, G. Cai, N. Huang, N. Yu, and Z. Huang, "An Efficient Probabilistic Approach Based on Area Grey Incidence Decision Making for Optimal Distributed Generation Planning," IEEE Access, 2019. 
[7] F. Abbasi, and S. M. Hosseini, "Optimal DG allocation and sizing in presence of storage systems considering network configuration effects in distribution systems," IET Gener. Transm. Distrib., vol. 10, pp. 617-624, 2016.

[8] H. B. Tolabi, M. H. Ali, and M. Rizwan, "Simultaneous Reconfiguration, Optimal Placement of DSTATCOM, and Photovoltaic Array in a Distribution System Based on FuzzyACO Approach,” IEEE Trans Sustain Energ, vol. 6, 2015.

[9] Z. Abdmouleh, A. Gastli, L. Ben-Brahim, M. Haouari, and N. A. Al-Emadi, "Review of optimization techniques applied for the integration of distributed generation from renewable energy sources," Renewable Energy, vol. 113, pp. 266-280, 2017.

[10] K. S. Sambaiah, "A Review on Optimal Allocation and Sizing Techniques for DG in Distribution Systems," Int Journal of Rene Energ Research, vol.8, no.3, 2018.

[11] D. Q. Hung, and N. Mithulananthan, "Loss reduction and loadability enhancement with DG: a dual-index analytical approach," Applied Energy, vol. 115, pp. 233-241, 2014.

[12] R. Viral,and D.K. Khatod, "An analytical approach for sizing and siting of DGs in balanced radial distribution networks for loss minimization,"Applied Energy, vol. 67, pp. 191-201, 2015.

[13] M. F. Shaaban, Y. M. Atwa, and E. F. ElSaadany, " DG allocation forbenefit maximization in distribution networks," IEEE Trans. Power Syst., vol. 28, pp. 639-649,2013.

[14] A.M. El-Zonkoly, "Optimal placement of multidistributed generation unitsincluding different load models using particle swarm optimization," SwarmEvol. Comput., vol. 1, pp.50-59, 2011.

[15] H. Falaghi, and M.R. Haghifam, "ACO based algorithm for distributedgeneration sources allocation and sizing in distribution systems," Power Tech, IEEE Lausanne, 2007.

[16] H. Piarehzadeh, A. Khanjanzadeh, and Reza Pejmanfer, "Comparison of harmony search algorithm and particle swarm optimization for distributed generation allocation to improve steady state voltage stability of distribution networks," Res. J. Appl. Sci. Eng. Technol., vol. 4,pp. 2310-2315, 2012.

[17] T. Sutthibun, and P. Bhasaputra, "Multiobjective optimal distributed generation placement using simulated annealing," Electrical Engineering/Electronics Computer Telecommunications and Information
Technology (ECTI-CON), International Conference on. IEEE, 2010.

[18] M.E. H. Golshan, and S.A. Arefifar, "Distributed generation, reactive sources and network-configuration planning for power and energy-loss reduction," IEE Proceed. Gener. Transm. Distrib., vol. 153,pp. 127-136, 2006.

[19] W. Sheng, K. Y. Liu, Y. Liu, X. Meng and Y. $\mathrm{Li}$, "Optimal Placement and Sizing of Distributed Generation via an Improved Non dominated Sorting Genetic Algorithm II", IEEE Trans Power Del, vol. 30, pp. 569-578, 2015.

[20] P. D. P. Reddy, V. C. V. Reddy, and T. G. Manohar, "Ant Lion optimization algorithm for optimal sizing of renewable energy resources for loss reduction in distribution systems", J. of Electrical Systems and Information Technology, 2017.

[21] K. Nadhir, D. Chabane, and B. Tarek, "Firefly algorithm based energy loss minimization approach for optimal sizing \& placement of distributed generation", 5th International Conference on Modeling, Simulation and Applied Optimization (ICMSAO), pp. 1-5, 2013.

[22] Z. Moravej, and A. Akhlaghi, "A novel approach based on cuckoo search for DG allocation in distribution network", Int. J. of Electrical Power \& Energy Systems, vol. 44, pp. 672-679, 2013.

[23] A. M. Shaheen, R. El Sehiemy, and S. M. Farrag, "A novel adequate bilevelreactive power planning strategy," Int. J. Electr. Power Energy Syst.,vol. 78, pp. 897-909, 2016.

[24] W. S. H. Sakr, "Enhancement of Power Quality in Deregulated Power Systems,"M.Sc, Tanta University, 2015.

[25] I. K. Sgouras, S. A. Bouhouras,A. P. Gkaidatzis, I. D. Doukas,and P. D Labridis, "Impact of reverse power flow on the optimal distributed generation placement problem," IET Gener Transm Distrib. Vol. 11, pp. 4626-4632, 2017

[26] H. A. Khattab, N. A. Zanaty, and S. M. Farrag, "Rehabilitation of Primary Distribution Networks Using Distributed Generation," Nineteenth International Middle East Power Systems Conference (MEPCON), Menoufia University, Egypt, pp. 270-276, 19-21 December 2017.

[27] A. Mishra , V. N. K. Gundavarapu,V. R. Bathina, andD. CDuvvada , "Real power performance index and line stability indexbased management of contingency using firefly algorithm,"IET Gener Transm Distrib, vol. 10, pp.2327-2335, 2016. 
[28] P. Siano, and G. Mokryani, "Assessing Wind Turbines Placement in a Distribution Market Environment by Using Particle Swarm Optimization," IEEE trans. on power systems, 2013.

[29] S. Nawaz, Dr. A. K. Bansal, Dr. M. P. Sharma, and A. Jain, "A Novel Index and Hybrid Optimization Approach for Optimal Placement of Multiple DGs in Reconfigured Distribution Networks," IEEE 4th International Conference on Power, Control \& Embedded Systems (ICPCES), 2017.

[30] S. R. Ghatak, S. Sannigrahi, and P. Acharjee, “ Comparative Performance Analysis of DG and DSTATCOM Using Improved PSO Based on Success Rate for Deregulated Environment," IEEE Systems Journal, 2017.

[31] J. H. Lee, J.W. Kim, J.Y. Song, D. W. Kim, Y. J. Kim, and S. Y. Jung, "Distance-based Intelligent Particle Swarm Optimization for Optimal Design of Permanent Magnet Synchronous Machine," IEEE Transactions on Magnetics, vol. 53, 2017.

[32] H. Shi, S. Liu, H. Wu, R. Li, S. Liu, N. Kwok, and Y. Peng, "Oscillatory Particle Swarm Optimizer," Applied Soft Computing Journal, vol. 73, pp. 316-327, 2018.

[33] A. Uniyala, and A. Kumar, "Optimal Distributed Generation Placement with Multiple Objectives Considering Probabilistic Load," Procedia Computer Science, Vol. 125, pp. 382388, 2018. 